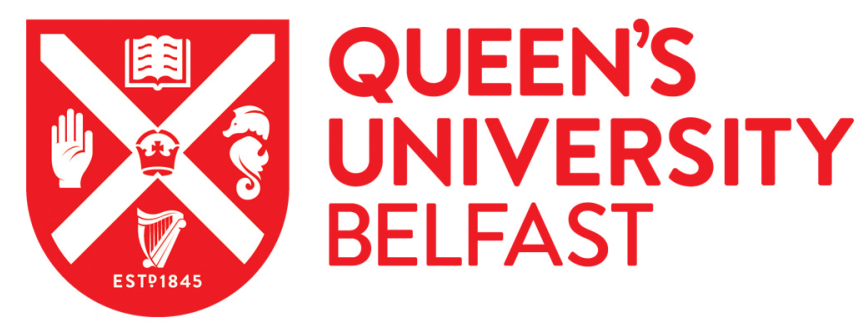

\title{
Cardiac disease and stroke: practical implications for personalised care in cardiac-stroke patients. A state of the art review supported by the Association of Cardiovascular Nursing and Allied Professions
}

Hendriks, J., Andreae, C., Agren, S., Hjelm, C., Walfridsson, U., Ski, C., Thylén, I., \& Jaarsma, T. (2020).

Cardiac disease and stroke: practical implications for personalised care in cardiac-stroke patients. A state of the art review supported by the Association of Cardiovascular Nursing and Allied Professions. European Journal of Cardiovascular Nursing. https://doi.org/10.1177/1474515119895734

Published in:

European Journal of Cardiovascular Nursing

Document Version:

Peer reviewed version

Queen's University Belfast - Research Portal:

Link to publication record in Queen's University Belfast Research Portal

Publisher rights

Copyright 2019 The Authors. This work is made available online in accordance with the publisher's policies. Please refer to any applicable terms of use of the publisher.

\section{General rights}

Copyright for the publications made accessible via the Queen's University Belfast Research Portal is retained by the author(s) and / or other copyright owners and it is a condition of accessing these publications that users recognise and abide by the legal requirements associated with these rights.

Take down policy

The Research Portal is Queen's institutional repository that provides access to Queen's research output. Every effort has been made to ensure that content in the Research Portal does not infringe any person's rights, or applicable UK laws. If you discover content in the

Research Portal that you believe breaches copyright or violates any law, please contact openaccess@qub.ac.uk. 


\section{Cardiac disease and stroke: practical implications for personalised care in cardiac-stroke patients - a state-of-the-art review}

Jeroen Hendriks ${ }^{1,2}$, Christina Andreae ${ }^{2,3}$, Susanna Ågren ${ }^{2,4}$, Helène Eriksson ${ }^{5}$, Carina Hjelm ${ }^{2,4}$, Ulla Walfridsson ${ }^{2,7}$, Chantal F. Ski ${ }^{8}$, Ingela Thylén ${ }^{7}$, Tiny Jaarsma ${ }^{5,6}$ (on behalf of the CESAR* network)

${ }^{1}$ Centre for Heart Rhythm Disorders, South Australian Health and Medical Research Institute, University of Adelaide and Royal Adelaide Hospital, Adelaide, Australia

${ }^{2}$ Department of Nursing, Faculty of Medical and Health Sciences, Linköping University, Linköping, Sweden

${ }^{3}$ Department of Medicine, Region Sörmland, 63188 Eskilstuna, Sweden

${ }^{4}$ Department of Cardiothoracic Surgery, Linköping University, Linköping, Sweden

${ }^{5}$ Department of Nursing, Faculty of Medical and Health Sciences, Linköping University, Linköping, Sweden

${ }^{6} J u l i u s$ Centrum University Medical Centre Utrecht, Utrecht, the Netherlands

${ }^{7}$ Department of Cardiology, Linköping University, Linköping, Sweden

${ }^{8}$ School of Nursing and Midwifery, Queen's University Belfast, Belfast, United Kingdom

${ }^{*}$ CESAR network: Collaboration and Exchange in Swedish cardiovascular caring Academic Research (CESAR) network. http://www.cesar-network.com/

This manuscript is supported by the Association of Cardiovascular Nurses and Allied Professions (European Society of Cardiology)

Word Count: 4049 (body, excluding abstract, tables/figure and references)

Address for Correspondence:

Professor T. Jaarsma

Department of Nursing, Faculty of Medical and Health Sciences, Linköping

Email: tiny.jaarsma@liu.se 


\begin{abstract}
Cardiac and stroke conditions often coexist because of common risk factors. The occurrence of stroke may have significant consequences for patients with cardiac conditions and their caregivers and poses a major burden on their lives. Although both cardiac and stroke conditions are highly prevalent, primary stroke prevention in cardiac patients is crucial to avert disabling limitations or even mortality. In addition, specific interventions may be needed in the rehabilitation and follow-up of these patients. However, healthcare systems are often fragmented and are not integrated enough to provide specifically structured and individualised management for the cardiac-stroke patient. Cardiac rehabilitation or secondary prevention services are crucial from this perspective, although referral and attendance rates are often suboptimal. This state-of-the-art review outlines the significance of primary stroke prevention in cardiac patients, highlights specific challenges that cardiac-stroke patients and their caregivers may experience, examines the availability of and need for structured, personalised care, and describes potential implications for consideration in daily practice.
\end{abstract}

\title{
Key words
}

Cardiac disease

Stroke

Cardiovascular risk factors

Hypertension

Self-care

Rehabilitation and prevention 


\section{Abbreviations}

$\mathrm{AF}$

Atrial Fibrillation

CVD Cardiovascular Disease

ESC European Society of Cardiology

HF Heart Failure

$\mathrm{ICH} \quad$ Intracerebral Haemorrhage

IHD Ischaemic Heart Disease

INR International Normalised Ratio

NOAC Non-Vitamin K Antagonist Oral Anticoagulation

OAC Oral Anticoagulation

PSD Post-Stroke Depression

PSF Post-Stroke Fatigue

QoL $\quad$ Quality of Life

SAH Subarachnoid Haemorrhage

TIA Transient Ischaemic Attack

WHO World Health Organisation 


\section{Introduction}

Over the past decade, ischaemic heart disease (IHD) and stroke have remained the top two causes of death, accounting for a combined mortality of 15.2 million individuals globally in 2016. ${ }^{1}$ Due to advances in treatment and specialised care, the incidence and mortality rates for both cardiovascular disease (CVD) and stroke have shown a decline over the past two decades, especially in the elderly; however, prevalence and morbidity rates have risen. ${ }^{2,3}$ Ageing is a key risk factor for CVD and stroke. ${ }^{4}$

Cardiac and stroke conditions commonly coexist due to an overlap of shared cardiovascular risk factors such as diabetes mellitus, hypertension, obesity, alcohol abuse, hypercholesterolemia and smoking. Exposure to these risk factors may lead to processes such as remodelling, coronary artery disease, or thrombus formation which ultimately may lead to stroke and cardiac conditions (Figure 1)..$^{5-7}$ The combination of both conditions is associated with poorer clinical outcomes compared to patients with stroke or a cardiac condition alone. As an example, hypertension is the most predominant cardiovascular risk factor for stroke, with a prevalence of $30 \%$ in developed nations. Hypertension relates to a continuous increased blood pressure in the arteries, causing damage to the cardiovascular system. Consequently, it leads to coronary artery disease which may be result in a cardiac or cerebrovascular event Hypertension is associated with both ischaemic and haemorrhagic stroke ${ }^{8}$ and the elderly population is more exposed to hypertension. ${ }^{9}$ Moreover, hypertension also promotes whitematter lesions, leading to silent brain infarctions which may cause functional and cognitive deficits. ${ }^{10}$

Heart failure (HF) is also considered an established risk factor for cerebral embolism due to the high risk of thromboembolic complications and increased activity of procoagulant factors. HF is associated with up to a three-fold increased risk of ischemic stroke and up to a 1.8-fold increased risk of all stroke subtypes in comparison with the general population. ${ }^{5}$ To illustrate, a large Danish study identified up to $16 \%$ of HF patients with a history of stroke. ${ }^{11}$ 
Finally, atrial fibrillation (AF) is significantly associated with the occurrence of thromboembolic stroke. Framingham data demonstrated a five-fold increased risk of stroke in AF patients compared to those without $\mathrm{AF}$ and up to $25 \%$ of all ischemic strokes are associated with AF. Moreover, AF-related thromboembolic/ischemic strokes are considered more severe, more disabling and more often fatal. ${ }^{4}$

These examples highlight the necessity of healthcare professionals who are caring for patients with cardiac conditions to have significant knowledge about strokes. This includes knowledge about prevention and treatment, but also about the consequences and potential impact of suffering a stroke on the patient's life. Individuals afflicted by stroke may suffer from a range of sequelae, with significant potential for impact on the management of their cardiac condition.

A recent position statement from the European Society of Cardiology (ESC) Council on Stroke described stroke as "a vascular disease with cerebral consequences, where the heart is a key player" (p. 1567). The document emphasises the role of the cardiologist in the prevention and treatment of stroke and concludes that a multidisciplinary approach is necessary to decrease the risk of stroke and to improve outcomes in stroke survivors. ${ }^{8}$ Multidisciplinary approaches are crucial; however, the question remains as to how to appropriately and effectively adapt cardiac care to stroke patients. Practice guidelines seldom address specific issues, focusing on living with the long-term consequences of chronic conditions such as stroke combined with cardiac disease. Patients with a history of stroke are likely to experience serious consequences that impact upon self-care maintenance and pose exacerbated challenges for cardiac-stroke survivors and their caregivers. To contribute to the optimisation of management of these complex and chronic conditions, we aim to describe the specific needs of cardiac patients with a history of stroke (cardiac-stroke patients) and identify current gaps in knowledge and care delivery.

This state-of-the-art review aims to: 1) outline the significance of primary stroke prevention in cardiac patients, 2) highlight specific daily life challenges for this patient group and their caregivers, 3) examine the need for structured, personalised follow-up care, and 4) 
describe potential implications for practice. In gathering evidence, this paper includes publications and reports with a variety of research designs, including randomised controlled trials (RCT), cross-sectional studies, and systematic reviews, as well as current practice guidelines.

\section{Primary stroke prevention in patients with cardiac conditions}

Strategies for preventing stroke are of great importance and range from reducing the risk of the emergence of stroke to preventing recurrences. The majority of cardiovascular risk factors are modifiable. It is significant that cardiovascular risk factors have been estimated to cause over $90 \%$ of stroke burden. ${ }^{12}$ Both cardiac conditions and stroke are primary contributors to a worse prognosis and quality of life (QoL), enhanced by their coexistence.

Professional clinical guidelines address the consequences of stroke for medical treatment. As such, the ESC guidelines for the diagnosis and treatment of acute and chronic HF state that the management of high-risk stroke patients may require balancing the risk of anticoagulant and antiplatelet therapies. ${ }^{13}$ Similarly, the ESC guidelines for the management of $\mathrm{AF}^{4}$ provide specific recommendations for medical treatment, with a particular focus on primary prevention of thromboembolic complications in patients with AF. It is recommended to use a risk stratification scheme, such as the $\mathrm{CHA}_{2} \mathrm{DS}_{2}$-VASc score, to predict the annual risk of stroke in these patients and to determine whether treatment with anticoagulation is warranted. $\mathrm{CHA}_{2} \mathrm{DS}_{2}-\mathrm{VASc}$ is an acronym referring to congestive $\mathrm{HF}$, hypertension, Age $\geq 75$ years, diabetes mellitus, prior stroke or transient ischaemic attack (TIA) or thromboembolism, vascular disease, age 65-74 years, and sex category (female gender), Table 2. It should be determined whether these conditions are present in the patient, adding 1 or 2 points per condition. Following the score calculation, it is then recommended that oral anticoagulation (OAC) therapy should be prescribed in men with a score $\geq 2$ and women with a score $\geq 3$. Treatment with OAC should also be considered in those patients with slightly elevated scores (i.e. men with a score $\geq 1$ and women with a score $\geq 2$ ). OAC treatment can either be with a vitamin K antagonist (Warfarin/Acenocoumarol), which requires International Normalised Ratio 
(INR) monitoring. An alternative is through the administration of a NOAC (Non-vitamin K Antagonist Oral Anticoagulant), such as Dabigatran, Apixaban, Rivaroxaban, or Edoxaban.

Effective treatment of hypertension is known to substantially decrease the incidence of stroke. ${ }^{14,15}$ Research has demonstrated that, for each $20 \mathrm{mmHg}$ systolic and 10 $\mathrm{mmHg}$ diastolic rise in circulatory strains, mortality resulting from stroke and ischemic illness increases twofold. On the other hand, it has been calculated that a $10 \mathrm{mmHg}$ decrease in systolic pressure and a $5 \mathrm{mmHg}$ decrease in diastolic pressure may prompt a $40 \%$ reduction in the risk of death caused by stroke. ${ }^{16}$

Therapeutic blood-pressure management in stroke survivors includes the acute stroke phase and the subsequent post-stroke phase. In acute ischaemic stroke, higher than normal blood pressure is accepted if not pursued in order to achieve sufficient intracranial perfusion pressure. During the post-stroke phase, it is not suggested to undergo pharmacological treatment until systolic pressures increase to more than $140 \mathrm{mmHg}$ as well as diastolic increases to over $90 \mathrm{mmHg}$ brain perfusion. The American Hypertension Guidelines ${ }^{17}$ specifically address blood-pressure management in adults with cerebral vascular disease/stroke. Hypertension management recommendations require the recognition of stroke acuity, stroke type, and therapeutic objectives, along with tailored antihypertensive medication and patient care that follows a structured, team-based approach.

\section{Potential daily life challenges for cardiac-stroke patients}

A chronic condition or a disabling event, such as a stroke, may significantly impact upon a patient's life, especially in terms of the coping and adaptation abilities of both patient and caregiver. In this section, the physical, cognitive and psychosocial challenges of having a cardiac condition and stroke will be outlined, as well as the impact of lifestyle modification and adherence to treatment regimen. 


\section{Challenges to physical functioning}

Challenge: The number and severity of comorbidities may increase the physical disability burden on patients.

Relationship with outcomes: Stroke can result in mobility limitations that night impact on the ability to attend cardiac rehabilitation programs (transportation issues) as well as participation in certain exercises. ${ }^{18}$ Moreover, multi-morbidity, which is highly prevalent in the majority of cardiac-stroke survivors in comparison to cardiac patients without stroke, may further complicate these processes. Limitations in mobility may also pose specific problems for symptom monitoring, such as identifying oedema or shortness of breath during exercise/activity. Regular weighing might be challenging due to balance or eyesight problems as a result of stroke. Patients may suffer from eating disorders post-stroke (e.g. affected appetite as a result of sensory changes) which might have consequences for maintaining optimal nutritional status. Dysphagia is a common symptom in stroke patients and a potential risk factor for malnutrition, ${ }^{19}$ which is also independently associated with dysphagia. ${ }^{20}$

\section{Challenges to cognitive functioning}

Challenge: Stroke is strongly associated with cognitive decline. In young ischaemic stroke patients (median age at index event 43), mental slowness was found to be present even up to 10 years after the event. Such cognitive deficits have been shown to have consequences for education and counselling even after long-term follow-up. ${ }^{21}$ In cardiac-stroke patients, the risk of cognitive impairment is even more elevated; about $80 \%$ of the stroke population struggles with memory and concentration problems, as well as problems with executive functions such as planning and problem-solving. ${ }^{22}$

Long-term cognitive outcomes for stroke patients show a decline in most cognitive domains in comparison to a non-stroke population. Significantly, up to $50 \%$ of patients were reported to have below-average performance or cognitive impairment, with deficits across processing speed, working memory and attention being most common, up to 11 years after their ischaemic stroke..$^{23}$ 
Relationship with outcomes: Providing lifestyle education and instruction, as well as structured follow-up for cardiac-stroke patients is crucial. Engagement with patients to investigate their needs, inclusive of illness beliefs, values and preferences, has the potential to improve lifestyle management and adherence to therapeutic regimen. ${ }^{24} \mathrm{~A}$ study of patients with HF showed that those with mild cognitive impairment had significantly lower self-care management and selfconfidence scores, which may impede a patient's ability to make appropriate self-care decisions. ${ }^{25}$

\section{Challenges to psychosocial functioning}

Challenge: Stroke and cardiac disease may cause significant worsening of QoL. Post stroke depression (PSD) is common. The underlying mechanisms of PSD can be related to coping with the consequences of stroke or with other processes such as inflammatory processes, genetic and epigenetic variations, white-matter disease, cerebrovascular deregulation, altered neuroplasticity, and changes in glutamate neurotransmission treatments. ${ }^{26}$

Alongside PSD, post-stroke fatigue (PSF) is a common problem among stroke survivors. Not surprisingly, cardiac and stroke patients rely heavily on support from their caregivers. ${ }^{27}$ Even though social support has been associated with lower levels of depression and better $\mathrm{QoL}^{28}$, it may add substantially to caregiver burden. For example, spouses of stroke survivors are reported to have low levels of QoL for up to seven years post-stroke onset, along with high levels of depressive symptoms (40\%) and anxiety symptoms $(21 \%) .^{29}$

Relationship with outcomes: Coping strategies and HRQoL are important outcome measures during the rehabilitative phase.$^{6,30}$ Awareness of the signs and symptoms of both PSD and PSF is crucial for the treatment and recovery phase. Patients may experience overwhelming feelings of fatigue (i.e. tiredness and lack of energy), ${ }^{31}$ which may impair their ability to regain lost functions ${ }^{32}$ and may potentially lead to negative long-term outcomes. Similarly, PSD mainly manifests as sadness, a reduction in interest and pleasure, and multiple psychological and vegetative symptoms. ${ }^{33}$ It afflicts $20-65 \%$ of these patients, depending on the population, the assessment measures, and the definition of depression. ${ }^{34}$ Research has 
demonstrated that those patients who experience PSD, the most common psychological sequel of stroke, benefit the least from rehabilitation, have the poorest QoL and a substantially increased risk of suicide. ${ }^{35}$

Similarly, negative emotional states such as depression and anxiety are highly prevalent in patients diagnosed with a cardiac condition and result in worse outcomes, e.g. poorer QoL and increased morbidity and mortality. ${ }^{36-38}$ In those with established cardiac conditions, frequently reported prevalence rates of depression are around $40 \%,{ }^{39,40}$ with some large-scale trials reporting over $60 \% .{ }^{41,42}$ As with stroke, factors impacting upon poorer prognosis of cardiac patients suffering from depression and anxiety are multifactorial and include lifestyle, behavioural (e.g. smoking, physical inactivity, and obesity) and biological (e.g. elevated cortisol levels, and markers of inflammation). ${ }^{36}$ Depression in cardiac patients is also a predictor of poor disease management and medication adherence. ${ }^{43,44}$ Consequently, negative patient outcomes (e.g. low QoL, depression, morbidity and mortality rates) are magnified in cardiac-stroke patients.

The disability level of stroke survivors has also been shown to effect the QoL of their spouses, which is likely caused by a combination of cognitive, physical and emotional factors. ${ }^{45}$ Caring for stroke survivors places considerable social, psychological, physical and financial strains on informal caregivers. These strains are known to fluctuate depending on the duration of the stroke, stroke survivor/caregiver intimacy, and length of daily caregiving. ${ }^{46}$ Additionally, such strains are exacerbated as the stroke survivor ages, often due to mounting cardiac conditions that require further lifestyle modifications.

\section{Challenges to lifestyle modifications and adherence to treatment}

Challenge: Most cardiac-stroke patients have a lifelong medication regimen and, notably, most medications require punctual intake (e.g. NOACs due to their short half-life). Importantly, patients should be empowered to pursue an active role in their care processes, which ultimately includes informed or shared decision-making. Patient education includes management of the condition, with a focus on high blood pressure, smoking, obesity, diabetes, 
hypercholesterolemia and lack of physical exercise. Successful management of risk factors not only reduces the risk of future cardiovascular events ${ }^{6}$ but has been shown to decrease the risk of cognitive deterioration as well. 47,48 Thus, active participation in self-care and rehabilitation is key to the recovery process. However, barriers for participation in rehabilitation of patients post-stroke exist and may include transportation issues, lack of interest and desiring a break from therapy. Also, patients may have severe cognitive deficits which would make them ineligible for participation. ${ }^{49}$ These factors should be considered prior commencing cardiac rehabilitation and also in the patient education and support for these patients.

Relationship with outcomes: Given the coexistence of multiple chronic conditions, treatment complexity is augmented and, with a diversity of healthcare professionals involved in the care of a patient, the risk of fragmented care is substantial. In addition, multiple hospital or rehabilitation visits may be difficult for patients with physical limitations or a poor caregiver network, which might have consequences for optimal treatment and follow-up.

\section{Structured, personalised care for the cardiac-stroke patient}

In cardiac-stroke patients, aims for treatment and care may need to be adapted to both chronic conditions. As such, ESC guidelines for the management of AF recommend a comprehensive treatment approach, including the management of arrhythmia, the modification of cardiovascular risk factors and the prevention of thromboembolic complications such as TIA or stroke. Applying such an integrated model, involving a multidisciplinary team and following a person-centred approach, would result in significant patient benefits in terms of improved QoL and life expectancy. ${ }^{4}$ Examples of these approaches have been utilised and tested, or at least recommended, in the fields of stroke, ${ }^{27} \mathrm{HF},{ }^{50}$ arrhythmia, ${ }^{51}$ and anticoagulation management. ${ }^{52}$ Within a multidisciplinary team approach the role of nurses and allied professionals is crucial. They are well placed to engage with the patient to identify needs and preferences, as well as to provide tailored education and coordination of care. At the same time, primary care and community healthcare interventions that focus on improving active follow-up and information provision to patients and caregivers, especially during the first year 
after stroke, could help improve patient self-management, increase stroke-specific health literacy and subsequently mitigate the current perceptions of abandonment felt by many stroke survivors and their caregivers. ${ }^{53}$

Disease management varies between countries, but is generally a combination of medical treatment and rehabilitation with a focus on physical activity, healthy lifestyle, selfcare education and strategies for psychosocial support, provided by a multidisciplinary team. Stroke may pose major consequences for the daily lives of cardiac patients and their families. Cardiac patients are often expected to pursue an active role in their own recovery and rehabilitation, implying significant lifestyle changes. A previous stroke (or a stroke during the cardiac disease trajectory) is likely to complicate and place major restrictions on daily activities and self-care behaviours.

Self-care is defined as a process of maintaining health through health-promoting practices and comprises three components. ${ }^{54}$ Self-care maintenance consists of behaviours utilised by patients to maintain physical and emotional stability; for example, reduce salt intake, take medication as prescribed, get a yearly flu shot, perform regular exercise, and maintain a healthy weight, particularly in HF patients. However, education on specific behaviours to help self-manage their condition and the associated risk factors, such as high blood pressure, diabetes, obesity and smoking, amongst others, is crucial. Cardiac rehabilitation, secondary prevention programmes or education programmes for cardiac patients address these specific behaviours, preferably using a person-centred approach. Adapting to required lifestyle patterns for both stroke and cardiac patients includes eating a healthy diet, engaging in aerobic activity, weight loss, restricting alcohol intake and stopping smoking. ${ }^{15,55}$ Self-care monitoring is the process of observing oneself for changes in signs and symptoms. In general, most cardiac patients are advised to monitor signs and symptoms of deterioration such as increased weight or oedema, recurrent chest pain in CAD patients, episodes of arrhythmia, or shortness of breath with activity. Patients can also self-monitor their blood pressure and heart rate, and be educated to recognise symptoms of a new thromboembolic or bleeding event (e.g. stroke, TIA). 
Self-care management refers to the evaluation of changes in physical and emotional factors in order to determine whether adjustment may be required. This refers to the patient's ability to adapt their self-care to changes in signs and symptoms related to the condition, or the development of new ones, as well as to evaluate the effectiveness (including unintentional side effects) of the treatment. Interpretation and decision-making are therefore considered important aspects of self-care management. Table 1 summarises crucial self-care aspects for cardiac-stroke patients.

\section{Implications for practice}

There is a paucity of literature on specific interventions for cardiac-stroke patients; trials often report on clinical outcomes such as hospitalisation and mortality, whilst patient-reported outcomes are scarce. However, the following recommendations have been extrapolated from the literature.

\section{Cardiac rehabilitation, risk-factor management and lifestyle modification}

Attending cardiac rehabilitation or secondary prevention programmes after a cardiac event is effective in decreasing mortality and morbidity rates, and improving QoL. ${ }^{56}$ Cardiac rehabilitation is a set of actions that are aimed at eliminating or minimising the impact of cardiac disease and related disabilities. ${ }^{7}$ Cardiac rehabilitation programs may differ but generally focus on reducing risk factors through lifestyle/behavioural modification, as well as improving exercise capacity and medication adherence. ${ }^{56}$ However, there are a number of barriers influencing referral to such programmes, and attendance rates are suboptimal. ${ }^{57}$ Additionally, cardiac rehabilitation programmes may need to be redesigned for cardiac-stroke survivors, facilitated by close collaboration between healthcare providers from different rehabilitation areas (e.g. neurology and cardiology), and might require a paradigm change. ${ }^{56}$ 


\section{$\underline{\text { Tailored self-care education, structured follow-up and multidisciplinary care }}$}

Recommendations on lifestyle modification, or adherence to the therapeutic regimen addressing both cardiac disease and stroke, might be a challenge for patients and their families. Person-centred education on therapeutic regimens should be tailored to cognitive abilities and should cover the need for such medication and that the requirements of strict adherence are crucial. ${ }^{58}$

The recent European Heart Rhythm Association Practical Guide to NOACs in patients with $\mathrm{AF}^{52}$ that emphasises the unique considerations posed by cognitive impairment to consent and adherence. This practical guide provides examples of once-daily medications, weekly tablet boxes, blister packing, reminders, or that others take care of providing the tablets as helpful tools ${ }^{52}$, while electronic monitoring should be studied further. ${ }^{13,59}$

Spouses and/or caregivers should be involved to support the patient's adherence. Structured follow-up in an appropriate setting (i.e. primary care practice, secondary care services) may contribute to improved treatment adherence and the prevention of non-persistence. At the same time, the treatment effects and side effects (e.g. bleeding, dizziness) of medication can be assessed. ${ }^{52}$

Given that the care for cardiac-stroke patients is complex, the question raises whether it is feasible for one single health care professional to deliver the care. Multidisciplinary care as part of novel care approaches is recommended by guidelines ${ }^{4,13}$ with crucial roles for nurses and allied professionals in terms of patient education, counselling and coordination of care. Importantly, considering a patient-centred approach requires active patient involvement in the care process with the patient being 'a member of the treatment team'.

Screening for comorbidities such as depression and cognitive problems is part of the multidisciplinary comprehensive approach. Randomised controlled trials for the prevention (PSD) have shown that antidepressants significantly decrease the incidence of PSD compared with placebo. Early antidepressant treatment of PSD appears to enhance both physical and cognitive recovery from stroke and might increase survival by up to 10 years following stroke. ${ }^{60}$ 
Assessment of cognitive functioning is also vital for the cardiac-stroke patient prior to decisions on flexible treatment regimens, such as intermittent diuretic management based on symptoms and weight in HF patients. Routine cognitive screening of cardiac patients, especially those with a history of stroke, should therefore be considered, and interventions consequently adapted to ensure patients adhere to their therapeutic regimen. There are numerous tools available for cognitive screening and the most commonly used include the Mini Mental State Exam (MMSE), the Montreal Cognitive Assessment (MoCa) and Cognitive abilities screening instrument.

In addition to these interventions there are several eHealth applications for patients and health care providers to support in understanding risk factors or help with selfcare. One example is the Stroke Riskometer application, where the user (i.e. patient or health care professional) can provide an indication on the risk of stroke and also compare the risk of having a stroke against persons of the same age and gender, but without risk factors (a new paradigm for primary prevention) ${ }^{61}$ It has been shown that the use of mobile applications has been effective in a stroke-affected population with obesity-related vascular risk factors who may otherwise be lost to physician follow-up. Using mobile applications is feasible for improving obesity management, health behaviour and adherence. ${ }^{62}$ Referring patients to use appropriate e-Health tools should be promoted as a relevant part of their education. However, health care professionals need to ensure the quality of the tools and appropriate time for instruction and feedback is available. ${ }^{63}$ The development of such tools and applications demonstrates the important value and evolution of integrating digital technology into clinical practice to support the empowerment of patients, with the primary goal of improving patient outcomes. However, e-Health applications are often very disease-specific and not always adapted to co-morbidity. Healthcare providers caring for cardiac-stroke patients can be instrumental in selecting suitable eHealth tools, with regard to both content and ease of use. 


\section{$\underline{\text { Involving and supporting the caregiver }}$}

Caregivers of cardiac-stroke patients are uniquely placed because they too have experienced sudden loss, grief - and often guilt. The caregiver role is one that is full of complexity because relationship roles are often reversed and unexpected challenges (e.g. mental, physical, financial) are experienced and may burden the caregiver, especially in the first 9 months of caregiving. ${ }^{64}$ It is therefore very important to emphasise the empowerment of spouses in their caregiver role, i.e. acting as enablers for spouses' health and wellbeing through personcentred care. ${ }^{65}$ Furthermore, highly strained caregivers may benefit from effective caregiver support programmes, which have been shown to be effective for spouses experiencing highly stressful caregiving. ${ }^{66}$ It is also important for informal caregivers to be involved in the rehabilitation plan for cardiac-stroke patients, with the inclusion of adequate attention to their own wellbeing. ${ }^{46}$

\section{Conclusion}

Patients who have suffered both cardiac disease and stroke often face complicated challenges that might not always be fully recognised by healthcare providers working in cardiology and neurology. Cardiac-stroke patients have worse mental and physical outcomes and prognoses; however, the current healthcare approach focuses on the two separate conditions. Given the increasing healthcare demands of cardiac-stroke patients, personalised interdisciplinary and integrated care models are necessary. Due to the specific needs and vulnerabilities of the cardiac-stroke population, comprehensive care and support should also be offered to caregivers, because they are an indispensable link in the care chain. We recommend that cardiac rehabilitation and secondary prevention, including risk-factor management, lifestyle modification and social support, should be provided to all cardiac-stroke survivors, and should be tailored to the individual patient's abilities, values and requirements. 
Figure and Table Legend

Table 1: Crucial self-care aspects for cardiac-stroke patients

Table 2: $\mathrm{CHA}_{2} \mathrm{DS}_{2}-\mathrm{VASc}$ score, clinical risk factors and scores

Figure 1: Common risk factors for stroke and cardiac conditions 


\section{References}

1. World Health Organization. Global Health Estimates 2016: Deaths by Cause, Age, Sex, by Country and by Region, 2000-2016. Geneva: World Health Organization; 2018.

2. Bhatnagar P, Wickramasinghe K, Wilkins E, Townsend N. Trends in the epidemiology of cardiovascular disease in the UK. Heart. 2016;102(24):1945-1952.

3. Koton S, Schneider AL, Rosamond WD, et al. Stroke incidence and mortality trends in US communities, 1987 to 2011. JAMA. 2014;312(3):259-268.

4. Kirchhof P, Benussi S, Kotecha D, et al. 2016 ESC Guidelines for the management of atrial fibrillation developed in collaboration with EACTS. Eur Heart J. 2016;37(38):2893-2962.

5. Adelborg K, Szepligeti S, Sundboll J, et al. Risk of Stroke in Patients With Heart Failure: A Population-Based 30-Year Cohort Study. Stroke. 2017;48(5):1161-1168.

6. Piepoli MF, Corra U, Adamopoulos S, et al. Secondary prevention in the clinical management of patients with cardiovascular diseases. Core components, standards and outcome measures for referral and delivery: a policy statement from the cardiac rehabilitation section of the European Association for Cardiovascular Prevention \& Rehabilitation. Endorsed by the Committee for Practice Guidelines of the European Society of Cardiology. Eur J Prev Cardiol. 2014;21(6):664-681.

7. Piepoli MF, Hoes AW, Agewall S, et al. 2016 European Guidelines on cardiovascular disease prevention in clinical practice: The Sixth Joint Task Force of the European Society of Cardiology and Other Societies on Cardiovascular Disease Prevention in Clinical Practice (constituted by representatives of 10 societies and by invited experts)Developed with the special contribution of the European Association for Cardiovascular Prevention \& Rehabilitation (EACPR). Eur Heart J. 2016;37(29):23152381. 
8. Widimsky P, Doehner W, Diener HC, et al. The role of cardiologists in stroke prevention and treatment: position paper of the European Society of Cardiology Council on Stroke. Eur Heart J. 2018;39(17):1567-1573.

9. Seshadri S, Debette S. Risk factors for cerebrovascular disease and stroke. Oxford, United Kingdom,: Oxford University Press; 2016.

10. Brambatti M, Connolly SJ, Gold MR, et al. Temporal relationship between subclinical atrial fibrillation and embolic events. Circulation. 2014;129(21):2094-2099.

11. Christiansen MN, Kober L, Weeke P, et al. Age-Specific Trends in Incidence, Mortality, and Comorbidities of Heart Failure in Denmark, 1995 to 2012. Circulation. 2017;135(13):1214-1223.

12. Feigin VL, Norrving B, Mensah GA. Global Burden of Stroke. Circ Res. 2017;120(3):439-448.

13. Ponikowski P, Voors AA, Anker SD, et al. 2016 ESC Guidelines for the diagnosis and treatment of acute and chronic heart failure: The Task Force for the diagnosis and treatment of acute and chronic heart failure of the European Society of Cardiology (ESC)Developed with the special contribution of the Heart Failure Association (HFA) of the ESC. Eur Heart J. 2016;37(27):2129-2200.

14. Hara A, Thijs L, Asayama K, Jacobs L, Wang JG, Staessen JA. Randomised doubleblind comparison of placebo and active drugs for effects on risks associated with blood pressure variability in the Systolic Hypertension in Europe trial. PLoS One. 2014;9(8):e103169.

15. Ravenni R, Jabre JF, Casiglia E, Mazza A. Primary stroke prevention and hypertension treatment: which is the first-line strategy? Neurol Int. 2011;3(2):e12.

16. Acharya T, Huang J, Tringali S, Frei CR, Mortensen EM, Mansi IA. Statin Use and the Risk of Kidney Disease With Long-Term Follow-Up (8.4-Year Study). Am J Cardiol. 2016;117(4):647-655.

17. Whelton PK, Carey RM, Aronow WS, et al. 2017 ACC/AHA/AAPA/ABC/ACPM/AGS/APhA/ASH/ASPC/NMA/PCNA Guideline for the 
Prevention, Detection, Evaluation, and Management of High Blood Pressure in Adults: A Report of the American College of Cardiology/American Heart Association Task Force on Clinical Practice Guidelines. J Am Coll Cardiol. 2018;71(19):e127e248.

18. Ades PA, Keteyian SJ, Balady GJ, et al. Cardiac rehabilitation exercise and self-care for chronic heart failure. JACC Heart Fail. 2013;1(6):540-547.

19. Chen N, Li Y, Fang J, Lu Q, He L. Risk factors for malnutrition in stroke patients: A meta-analysis. Clin Nutr. 2019;38(1):127-135.

20. Saito T, Hayashi K, Nakazawa H, Yagihashi F, Oikawa LO, Ota T. A Significant Association of Malnutrition with Dysphagia in Acute Patients. Dysphagia. 2018;33(2):258-265

21. de Bruijn MA, Synhaeve NE, van Rijsbergen MW, de Leeuw FE, Jansen BP, de Kort PL. Long-term cognitive outcome of ischaemic stroke in young adults. Cerebrovasc Dis. 2014;37(5):376-381.

22. Sun JH, Tan L, Yu JT. Post-stroke cognitive impairment: epidemiology, mechanisms and management. Ann Transl Med. 2014;2(8):80.

23. Schaapsmeerders P, Maaijwee NA, van Dijk EJ, et al. Long-term cognitive impairment after first-ever ischemic stroke in young adults. Stroke. 2013;44(6):16211628.

24. Ferguson C, Hendriks J. Partnering with patients in shared decision-making for stroke prevention in atrial fibrillation. Eur J Cardiovasc Nurs. 2017;16(3):178-180.

25. Cameron J, Worrall-Carter L, Page K, Riegel B, Lo SK, Stewart S. Does cognitive impairment predict poor self-care in patients with heart failure? Eur J Heart Fail. 2010;12(5):508-515.

26. Villa RF, Ferrari F, Moretti A. Post-stroke depression: Mechanisms and pharmacological treatment. Pharmacol Ther. 2018;184:131-144.

27. Ski CF, Castle DJ, Lautenschlager NT, Moore G, Thompson DR. Caring for caregivers after a stroke. Int Psychogeriatr. 2015;27(1):1-4. 
28. Tramonti F, Fanciullacci C, Giunti G, Rossi B, Chisari C. Functional status and quality of life of stroke survivors undergoing rehabilitation programmes in a hospital setting. NeuroRehabilitation. 2014;35(1):1-7.

29. Loh AZ, Tan JS, Zhang MW, Ho RC. The Global Prevalence of Anxiety and Depressive Symptoms Among Caregivers of Stroke Survivors. J Am Med Dir Assoc. $2017 ; 18(2): 111-116$

30. Lo Buono V, Corallo F, Bramanti P, Marino S. Coping strategies and health-related quality of life after stroke. J Health Psychol. 2017;22(1):16-28.

31. Brodtmann A, van de Port IG. Fitness, depression, and poststroke fatigue: worn out or weary? Neurology. 2013;81(18):1566-1567.

32. Tang WK, Chen YK, Mok V, et al. Acute basal ganglia infarcts in poststroke fatigue: an MRI study. J Neurol. 2010;257(2):178-182.

33. Li M, Zhang XW, Hou WS, Tang ZY. Impact of depression on incident stroke: a metaanalysis. Int J Cardiol. 2015;180:103-110.

34. De Ryck A, Brouns R, Geurden M, Elseviers M, De Deyn PP, Engelborghs S. Risk factors for poststroke depression: identification of inconsistencies based on a systematic review. J Geriatr Psychiatry Neurol. 2014;27(3):147-158.

35. Pompili M, Venturini $\mathrm{P}$, Campi S, et al. Do stroke patients have an increased risk of developing suicidal ideation or dying by suicide? An overview of the current literature. CNS Neurosci Ther. 2012;18(9):711-721.

36. Dhar AK, Barton DA. Depression and the Link with Cardiovascular Disease. Front Psychiatry. 2016;7:33.

37. Freedland KE, Carney RM, Rich MW, Steinmeyer BC, Rubin EH. Cognitive Behavior Therapy for Depression and Self-Care in Heart Failure Patients: A Randomized Clinical Trial. JAMA Intern Med. 2015;175(11):1773-1782.

38. Gale CR, Batty GD, Osborn DP, Tynelius P, Rasmussen F. Mental disorders across the adult life course and future coronary heart disease: evidence for general susceptibility. Circulation. 2014;129(2):186-193. 
39. Colquhoun DM, Bunker SJ, Clarke DM, et al. Screening, referral and treatment for depression in patients with coronary heart disease. Med J Aust. 2013;198(9):483484.

40. Seldenrijk A, Vogelzangs N, Batelaan NM, Wieman I, van Schaik DJ, Penninx BJ. Depression, anxiety and 6-year risk of cardiovascular disease. J Psychosom Res. $2015 ; 78(2): 123-129$.

41. Carney RM, Blumenthal JA, Freedland KE, et al. Depression and late mortality after myocardial infarction in the Enhancing Recovery in Coronary Heart Disease (ENRICHD) study. Psychosom Med. 2004;66(4):466-474.

42. Kotseva K, Wood D, De Backer G, et al. EUROASPIRE III: a survey on the lifestyle, risk factors and use of cardioprotective drug therapies in coronary patients from 22 European countries. Eur J Cardiovasc Prev Rehabil. 2009;16(2):121-137.

43. Bauer LK, Caro MA, Beach SR, et al. Effects of depression and anxiety improvement on adherence to medication and health behaviors in recently hospitalized cardiac patients. Am J Cardiol. 2012;109(9):1266-1271.

44. Goldstein CM, Gathright EC, Garcia S. Relationship between depression and medication adherence in cardiovascular disease: the perfect challenge for the integrated care team. Patient Prefer Adherence. 2017;11:547-559.

45. Persson J, Holmegaard L, Karlberg I, et al. Spouses of Stroke Survivors Report Reduced Health-Related Quality of Life Even in Long-Term Follow-Up: Results From Sahlgrenska Academy Study on Ischemic Stroke. Stroke. 2015;46(9):2584-2590.

46. Gbiri CA, Olawale OA, Isaac SO. Stroke management: Informal caregivers' burdens and strians of caring for stroke survivors. Ann Phys Rehabil Med. 2015;58(2):98-103.

47. Plassman BL, Williams JW, Jr., Burke JR, Holsinger T, Benjamin S. Systematic review: factors associated with risk for and possible prevention of cognitive decline in later life. Ann Intern Med. 2010;153(3):182-193.

48. Sahathevan R, Brodtmann A, Donnan GA. Dementia, stroke, and vascular risk factors; a review. Int J Stroke. 2012;7(1):61-73. 
49. Marzolini S, Fong K, Jagroop D, et al. Eligibility, Enrollment, and Completion of Exercise-Based Cardiac Rehabilitation Following Stroke Rehabilitation: What Are the Barriers? Phys Ther. 2019.

50. Healy L, Ledwidge M, Gallagher J, Watson C, McDonald K. Developing a disease management program for the improvement of heart failure outcomes: the do's and the don'ts. Expert Rev Cardiovasc Ther. 2019;17(4):267-273.

51. Gallagher C, Elliott AD, Wong CX, et al. Integrated care in atrial fibrillation: a systematic review and meta-analysis. Heart. 2017;103(24):1947-1953.

52. Steffel J, Verhamme P, Potpara TS, et al. The 2018 European Heart Rhythm Association Practical Guide on the use of non-vitamin K antagonist oral anticoagulants in patients with atrial fibrillation. Eur Heart J. 2018;39(16):1330-1393.

53. Pindus DM, Mullis R, Lim L, et al. Stroke survivors' and informal caregivers' experiences of primary care and community healthcare services - A systematic review and meta-ethnography. PLoS One. 2018;13(2):e0192533.

54. Riegel B, Jaarsma T, Stromberg A. A middle-range theory of self-care of chronic illness. ANS Adv Nurs Sci. 2012;35(3):194-204.

55. He FJ, Nowson CA, MacGregor GA. Fruit and vegetable consumption and stroke: meta-analysis of cohort studies. Lancet. 2006;367(9507):320-326.

56. Woodruffe S, Neubeck L, Clark RA, et al. Australian Cardiovascular Health and Rehabilitation Association (ACRA) core components of cardiovascular disease secondary prevention and cardiac rehabilitation 2014. Heart Lung Circ. $2015 ; 24(5): 430-441$

57. Bennett KK, Smith AJ, Harry KM, et al. Multilevel Factors Predicting Cardiac Rehabilitation Attendance and Adherence in Underserved Patients at a Safety-Net Hospital. J Cardiopulm Rehabil Prev. 2019;39(2):97-104.

58. Gallagher C, Rowett D, Nyfort-Hansen K, et al. Patient-Centered Educational Resources for Atrial Fibrillation. JACC Clin Electrophysiol. 2019;5(10):1101-1114. 
59. Desteghe L, Vijgen J, Koopman P, et al. Telemonitoring-based feedback improves adherence to non-vitamin $\mathrm{K}$ antagonist oral anticoagulants intake in patients with atrial fibrillation. Eur Heart J. 2018;39(16):1394-1403.

60. Robinson RG, Spalletta G. Poststroke depression: a review. Can J Psychiatry. $2010 ; 55(6): 341-349$.

61. Krishnamurthi R, Hale L, Barker-Collo S, et al. Mobile Technology for Primary Stroke Prevention. Stroke. 2018:STROKEAHA118023058.

62. Ifejika NL, Noser EA, Grotta JC, Savitz SI. Swipe out Stroke: Feasibility and efficacy of using a smart-phone based mobile application to improve compliance with weight loss in obese minority stroke patients and their carers. Int J Stroke. 2016;11(5):593603.

63. Klompstra L, Johansson Ostbring M, Jaarsma T, et al. The Appropriateness and Presentation of Commonly Available Cardiovascular Web Pages Providing Information About Cardiovascular Diseases. Comput Inform Nurs. 2019;37(10):493497.

64. Pucciarelli G, Ausili D, Galbussera AA, et al. Quality of life, anxiety, depression and burden among stroke caregivers: A longitudinal, observational multicentre study. $J$ Adv Nurs. 2018.

65. Abzhandadze T, Forsberg-Warleby G, Holmegaard L, et al. Life satisfaction in spouses of stroke survivors and control subjects: A 7-year follow-up of participants in the Sahlgrenska Academy study on ischaemic stroke. J Rehabil Med. 2017;49(7):550-557.

66. Haley WE, Roth DL, Howard G, Safford MM. Caregiving strain and estimated risk for stroke and coronary heart disease among spouse caregivers: differential effects by race and sex. Stroke. 2010;41(2):331-336. 
Self-care maintenance: Those behaviours used by patients with a chronic illness to maintain physical and emotional stability

- Healthy diet

- Restricted alcohol intake

- Take medication (adherence)

- Pill in the pocket approach (anti-arrhythmia medication)

- Exercise /activity /training

- Vaccination

- Smoking cessation

- Risk Factor Modification (hypertension, diabetes, dyslipidaemia, obesity, sleep apnoea).

Self-care monitoring: The process of observing oneself for changes in signs and symptoms

- Monitor body weight

- Monitor dyspnea, oedema etc

- Monitor side effect and complications

- Monitor Skin problems

- Monitor signs of low mood /Depression and anxiety *

- Monitoring of symptoms

- Monitor recommended vital signs (BP, pulse)

- Self INR monitoring in patients on Warfarin

Self-care management: The response to signs and symptoms when they occur

- Increase diuretics when needed

- Call health care provider in case of increase of symptoms or new problems

- Adjust diet

- Adjust activity level

- $\quad$ Pill in the pocket approach (anti-arrhythmia medication)

Table 1 


\begin{tabular}{|c|c|}
\hline $\mathrm{CHA}_{2} \mathrm{DS}_{2}-\mathrm{VASc}$ risk factor & Points \\
\hline $\begin{array}{l}\text { Congestive heart failure } \\
\text { Signs/symptoms of heart failure or objective evidence of } \\
\text { reduced left ventricular ejection fraction }\end{array}$ & +1 \\
\hline $\begin{array}{l}\text { Hypertension } \\
\text { Resting blood pressure }>140 / 90 \mathrm{mmHg} \text { on at least two } \\
\text { occasions or current antihypertensive treatment }\end{array}$ & +1 \\
\hline Age 75 years or older & +2 \\
\hline $\begin{array}{l}\text { Diabetes mellitus } \\
\text { Fasting glucose }>125 \mathrm{mg} / \mathrm{dL}(7 \mathrm{mmol} / \mathrm{L}) \text { or treatment } \\
\text { with oral hypoglycaemic agent and/or insulin }\end{array}$ & +1 \\
\hline $\begin{array}{l}\text { Previous stroke, transient ischaemic attack, or } \\
\text { thromboembolism }\end{array}$ & +2 \\
\hline $\begin{array}{l}\text { Vascular disease } \\
\text { Previous myocardial infarction, peripheral artery disease, } \\
\text { or aortic plaque }\end{array}$ & +1 \\
\hline Age $65-74$ years & +1 \\
\hline Sex category (female) & +1 \\
\hline
\end{tabular}

Table 2 (adapted from Kirchhof et al, European Heart Journal 2016) ${ }^{4}$ 


\begin{tabular}{l}
\hline $\begin{array}{l}\text { Risk factors for stroke and } \\
\text { cardiac conditions }\end{array}$ \\
\hline Aging \\
Hypertension \\
\hline Diabetes Mellitus \\
Hyperlipidaemia \\
\hline Ischemic Heart Disease \\
\hline Valvular Heart Disease \\
\hline Obesity \\
\hline Smoking \\
\hline Alcohol abuse \\
\hline
\end{tabular}

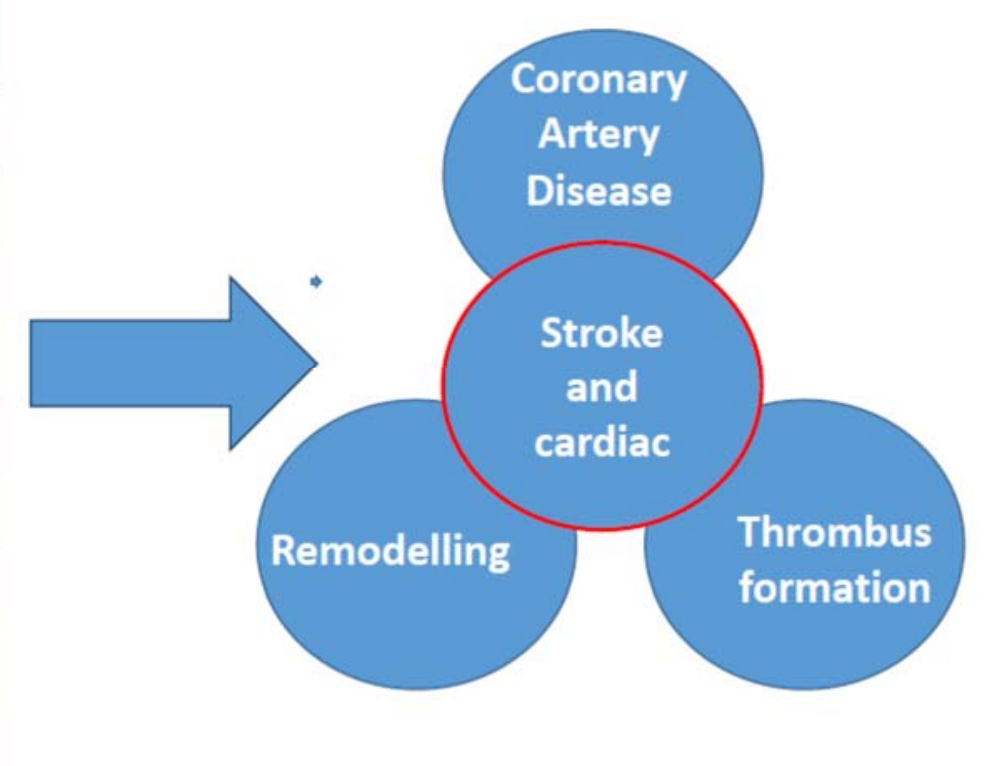

Figure 1 